\title{
Smart Identification System for Motor Vehicles Subsidized Fuel Restriction
}

\author{
Indrastanti R. Widiasari \\ Faculty of Information Technology \\ Satya Wacana Christian University \\ J. Diponegoro 52-60 Salatiga
}

\author{
Dian Widiyanto Chandra \\ Faculty of Information Technology \\ Satya Wacana Christian University \\ Jl. Diponegoro 52-60 Salatiga
}

\begin{abstract}
The Indonesian government policy to provide subsidized fuel usage restrictions encountered abuse problems that required a system that can help the process of monitoring the implementation of the fuel subsidy restrictions. The use of smart labels on this system makes the vehicle identification can be performed more quickly and may preclude possible fraud related to the use of subsidized fuel restriction policy.
\end{abstract}

\section{General Terms}

Your general terms must be any term which can be used for general classification of the submitted material such as Pattern Recognition, Security, Algorithms et. al.

\section{Keywords}

Fuel subsidy, smart label, Vehicle identification

\section{INTRODUCTION}

Since 2012 the Government of Indonesia has been imposing policy of restrictions on the use of fuel oil (BBM). Stateowned oil company of Indonesia (PERTAMINA) as related party determined three criteria of unauthorized vehicles using subsidized fuel which are red vehicle registration plate, military and police vehicle registration plate, and special purpose vehicles [1]. On the other hand, the use of subsidized fuel restriction options is considered ineffective because the operational cost of surveillance system is so high, but the result is not effective [2]. Supervision of subsidized fuel distribution which has been done by Board Committee on Downstream Oil and Gas (BPH Migas) and local government, until now still continue to make improvements. So that it is needed to build a smart system which could assist in the supervision of the implementation of the fuel subsidy restrictions.

Based on this background, this research will develop a new system for monitoring the implementation of subsidized fuel restrictions. Intelligent Systems for vehicle registration plate can be used to indentify an unauthorized vehicle use subsidized fuel or not. The system can record the identity of the vehicle, so it will be known whether the vehicle qualifies as an unauthorized vehicle use subsidized fuel or not. By using the Smart Label detection, process vehicle can be done quickly and can diminish the chance of occurrence fraud related to the use of subsidized fuel restriction policy.

\section{RELATED WORK}

Some research which are related to the use of Radio Frequency Identification technology (RFID) has been a lot done, such as for monitoring the food condition [3], to control the logistics field [4], as well as for tracking and monitoring the goods delivery [5]. In the integrated use of smart labels which is used to track food information and monitoring the condition of food, using humidity, temperature, and light intensity sensor interface circuit with A / D converter and a 13.56-MHz RFID transponder for transmitting and receiving data, and to collect from the external reader energy for recharging on-board and turn on the transmitter micro battery. The proposed system, designed in a 0.18 -mum CMOS technology, the simulation achieving the required performance, in terms of functionality, accuracy, and power consumption [3]. Other studies on the use of RFID smart tag for traceability of food temperatures in this case the fresh fish. The primary objective of this study was the validation of RFID smart tag developed for real-time tracking and monitoring of the cold chain for food applications. RFIDbased system consists of a commercial smart tag and reader/writer. Smart tag attached to the product to be tracked which integrates light sensor, temperature and humidity, microcontroller, memory chip, low-power electronics and antennas for RFID communication. Log sensor data can be stored in memory along with the tracking data. A reader/writer is used to read and write data on the smart tag, the wireless reading distance of $10 \mathrm{~cm}$, in real-time at any time of the food chain. Experiment is the system uses fresh fish which proves that this system presents important advantages compared to conventional search tools and temperature data logger, memory, among other advantages, the usefulness, the absence of the role of humans, there is no visibility of tags needed for reading, the possibility of reading many tags at a time simultaneously and resistance to moisture foods and environmental conditions [6].

\section{RFID SMART TAG}

There are various kinds of antenna design labels, each with a type of own characteristics. Antenna design is influenced by various elements, such as the area label operation (near or far), the field of electricity (electric field or magnetic field), the constraints regulation, and the environment in which the equipment will be operated. For example, a environment with many metal-containing structures can affect the time varying electromagnetic fields, thus affecting the performance of the antenna. Designing antenna in accordance with the structure of the metal will require special consideration. An aspect of importance of the design process is to allow the maximum distance between the reader antenna and label antenna [3].

\section{TAG ANTENNA DESIGN CONSIDERATIONS}

The use of RFID in identification of objects in various types of systems will be widely used to various places around the world. On the product packaging for consumers to use new ways ie by integrating the RFID label into the packaging, labels develop appropriate packaging, and the contents of packaged goods [3]. In previous studies on the design of the 
antenna, there are numerous publications on the RFID tag antenna, both of which use active tags and passive tags like Slot Antenna Design [7], the F-antenna design Reversed [8] and Design Fold Dipole antenna [9], to consider some of the most relating to this publication only covers aspects of antenna analysis and practical aspects such as the suitability of the antenna for a particular application [10]. However, that is not covered is a methodology to design the tag antenna and a clear view of the design criteria for the tag antenna. A discussion of the research aims to bridge the differences in knowledge of the tag antenna. In another study of RFID labels can be placed on a corrugated cardboard box containing dry goods. Antenna design presented a credit card-sized deemed suitable size for labels in most cases used in supply chain applications.

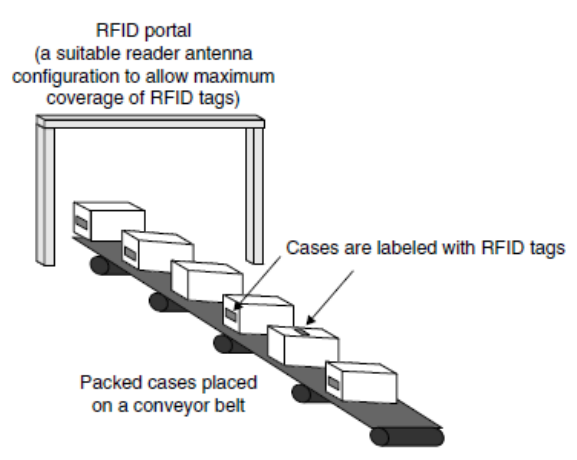

Fig 1: Penggunaan Label RFID pada Aplikasi Supply Chain

\section{RFID DESIGN METHODOLOGY}

A simple approach is to consider a single element or two element matching network that will change the impedance of the antenna to form a conjugate match to the impedance of the chip. As the matching network must then physically implemented as part of the antenna due to the use of lumped circuit elements are separate, lossy expensive, and less efficient method area. RFID tags produced certainly tend to be too complex for analytical investigation and various numerical electromagnetic analysis software based on the method of moments for the two-dimensional planar structure (MoM), finite element method (FEM), or finite difference time domain (FDTD) method for more complicated structures three dimensions may be used. Before using design tools, it is essential to develop strategies and evaluate the performance simulation tool by comparing simulation results with those from the analysis and measurement results. Then, a new antenna design can be modeled and simulated to obtain the desired antenna gain, input impedance, and to understand the relationship between the dimensions of the tag antenna and the antenna input impedance, which is very important to provide the maximum power to the tag.

Once the optimal antenna design has been developed, the prototype of the antenna can be constructed and their performance can be evaluated by measuring the read range under controlled conditions (such as an anechoic chamber) or in a practical environment in which the tag will be deployed. In terms of the design of the tag is not satisfactory, the whole process of design iterations needed to obtain adequate antenna performance. The following sections describe, in detail, the two tag antenna design suitable for tagging cases in supply chain applications, as required in the fast moving consumer goods (FMCG) applications.

\section{IMPLEMENTATION}

This research uses several labels which are tested as shown in Figure 1. Each label has a memory capacity of 496 bytes, which is used to store motor vehicle information. The allocation of memory (memory mapping) on this system as shown in Table 1. Information about the contents of the vehicle is made in accordance with the Certificate of Number Vehicle (vehicle registration) and Certificate of Motor Vehicle Owner for further research directions are building prototypes of e- Certificate of Number Vehicle.

Table 1. Memory Requirements on Motor Vehicle Identification Label Systems

\begin{tabular}{|c|c|c|c|}
\hline Field Name & Field Length & Example & information \\
\hline Vehicle registration Number & $\begin{array}{l}9 \text { digit (without -) or } 11 \\
\text { digit (with -) }\end{array}$ & AB-1234-CDE & \\
\hline Owner's name & 20 & & \\
\hline Addres5 & 50 & & \\
\hline Job & 20 & & \\
\hline D Number & 19 & & \\
\hline Brand & 2 & Honda & Lookup table \\
\hline Type & 15 & NF11B1D MT & \\
\hline Category & 2 & MOTOR CYCLE & Lookup table \\
\hline Model & 2 & Solo & Lookup table \\
\hline Year of manufacturing & 4 & 2013 & \\
\hline Cylinder capacity & $\begin{array}{l}6 \text { digit (without -) or } 7 \\
\text { digit (with -) }\end{array}$ & $1299-C C$ & \\
\hline Vehicle Identification Number & 17 & & \\
\hline Vehicle Engine Number & 12 & & \\
\hline Color & 2 & BLACK & Lookup table \\
\hline Fuel & 2 & Gasoline & Lookup table \\
\hline $\begin{array}{l}\text { Color of registration vehicle } \\
\text { number }\end{array}$ & 2 & BLACK & Lookup table \\
\hline Year of Registration & 4 & 2013 & \\
\hline $\begin{array}{l}\text { Certificate of Motor Vehicle } \\
\text { Owner Number }\end{array}$ & 10 & & \\
\hline Number of axis & 1 & 6 (trailer) & \\
\hline Number of Wheel & 2 & 22 (trailer) & \\
\hline Invoice Number & 14 & & \\
\hline \multirow[t]{2}{*}{ Inporter } & 20 & & \\
\hline & \multicolumn{3}{|c|}{ TOLLBOOTH INFORMATION } \\
\hline \multicolumn{4}{|l|}{ PIB number } \\
\hline \multirow{2}{*}{\multicolumn{4}{|c|}{$\begin{array}{l}\text { SUT number } \\
\text { TPT number }\end{array}$}} \\
\hline & & & \\
\hline $\begin{array}{l}\text { TPT number } \\
\text { Fom } A / B / C \text { numbers }\end{array}$ & & & $\begin{array}{l}\text { built up } \\
\text { vehicle }\end{array}$ \\
\hline \multicolumn{4}{|l|}{ Office of Customs } \\
\hline \multicolumn{4}{|l|}{ Auction Number } \\
\hline \multicolumn{4}{|l|}{ Skep DUM TNI POLRI number } \\
\hline \multirow{2}{*}{\multicolumn{4}{|c|}{$\begin{array}{l}\text { CHANGE OF IDENTITY } \\
60\end{array}$}} \\
\hline & & & \\
\hline Type of Change & 2 & $\begin{array}{l}\text { change of vehicle } \\
\text { identification number }\end{array}$ & Lookup Table \\
\hline Released in & 15 & Ujung Pandang & \\
\hline Date & 10 & $31-12-2013$ & \\
\hline \multicolumn{4}{|c|}{ POLICE NOTES } \\
\hline Police Notes & 3 & $\begin{array}{l}\text { Ma Jaya certificate } \\
\text { No. } 123456 \text { date } 31 \text { - } \\
12-2013 \text { says that the } \\
\text { vehicle has changed } \\
\text { the shape of the light }\end{array}$ & $\begin{array}{l}\text { Used for } \\
\text { police notes }\end{array}$ \\
\hline
\end{tabular}

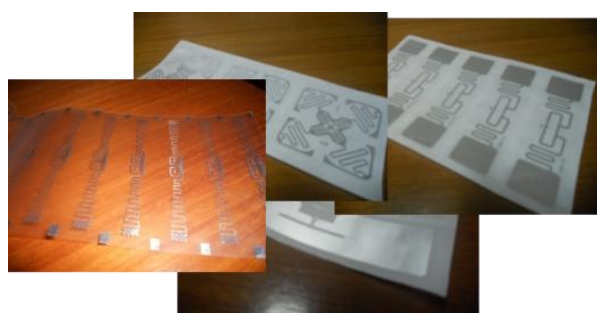

Fig 2: RFID tag (Label)

\section{RESULT}

The smart system of motor vehicle identification system has two parts, namely the system itself which consists of a reader and smart labels, and information systems as the user interface. The information system is illustrated in Figure 3, allows the administrator to enter vehicle data on the label and in Figure 4 is a display on the user side. 


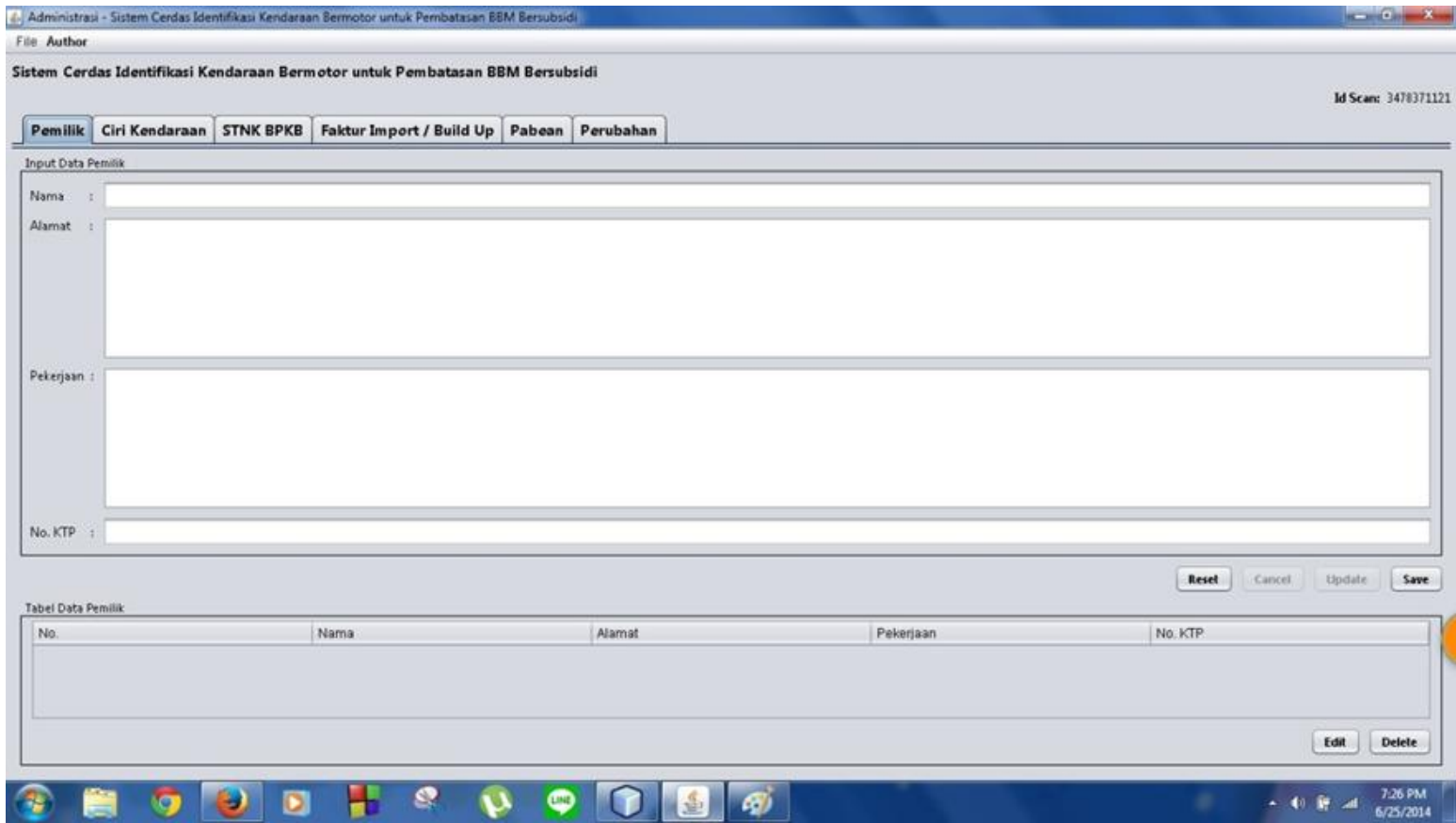

Fig 3: Administrator Interface

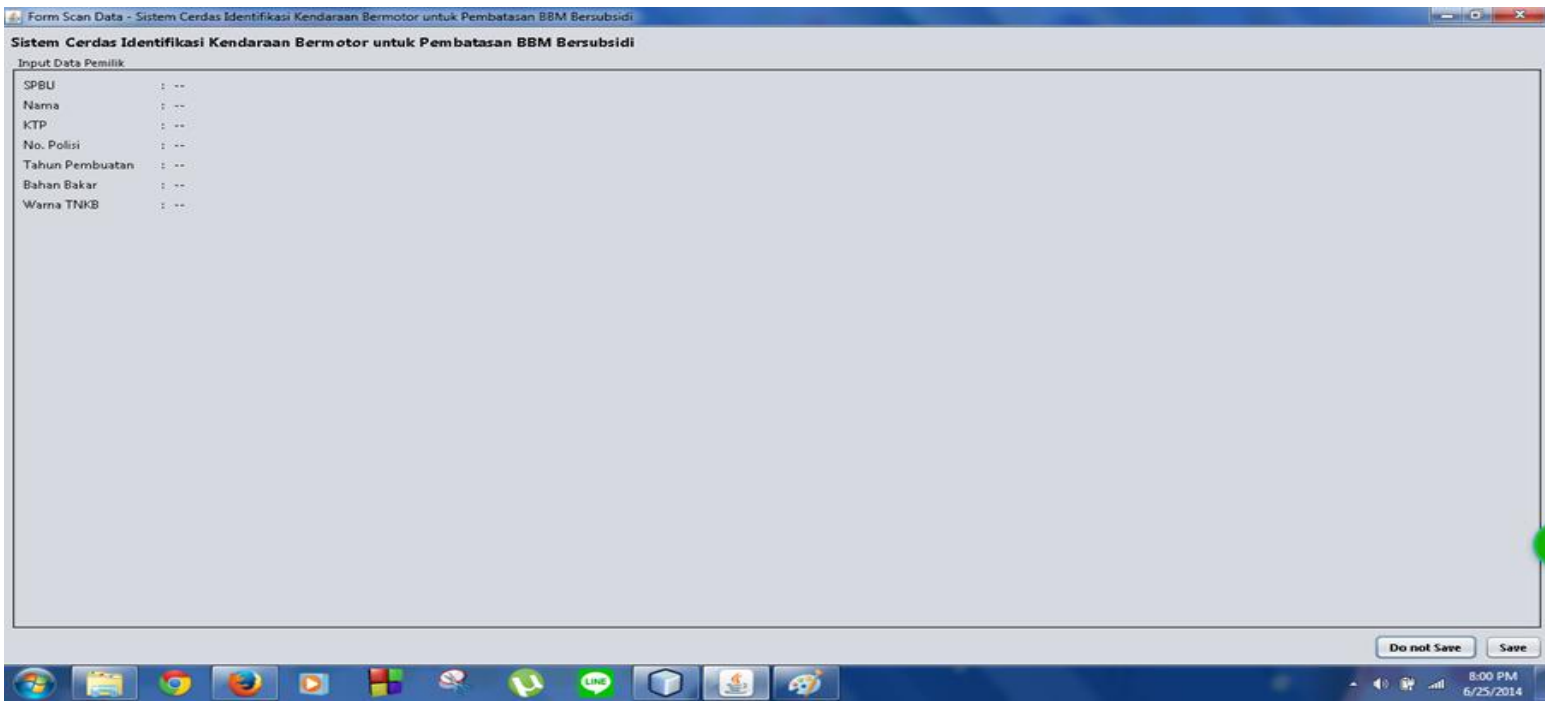

Fig 4: Administrator Interface

Figure 5 shows Home page. On this page you will be able to choose between entering as a gas station and as Administrator, by selecting the combo box "Sign In".

Figure 6 shows the gas station Page display. This is the main display used by the gas station attendant. On this page it shows the important data range of the RFID reader. Each officer serves buyers fuel filling stations are required to press the "layani" and will be asked to enter the number of liters of fuel to be purchased, as shown in Figure 6. (No. Plate, Total Buy Gasoline, Vehicle Type, Eligibility, Smart Card ID Label) vehicles within range of the RFID reader. Each officer serves buyers fuel filling stations are required to press the "layani" and will be asked to enter the number of liters of fuel to be purchased, as shown in Figure 6. The amount of fuel which is purchased by a buyer per day will be recorded in the column "Total Bensin Beli", which aims to limit to only 3 liters of gasoline which can be purchased by the buyer. In each data record is a button "View" whose purpose is to display the data more specific buyer. See Figure 7.

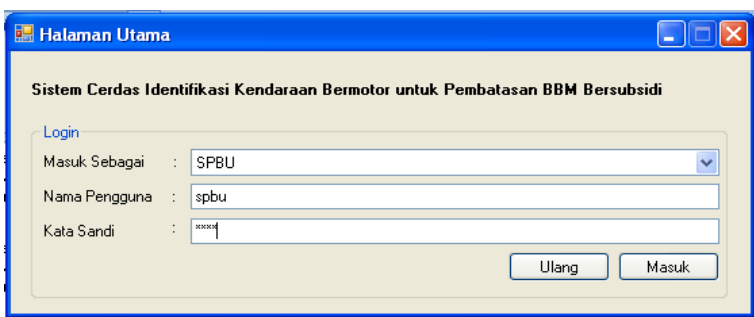

Fig 5: Home page

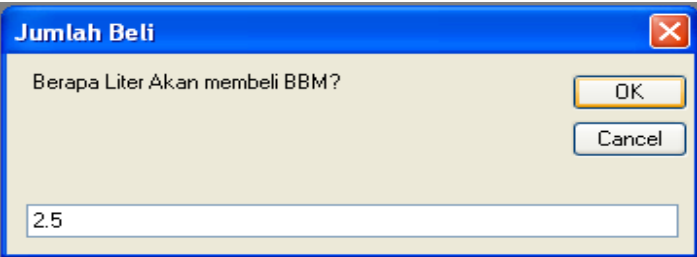

Fig 6: Amount of fuel-to- purchase Form 
Administrator Form is the main page where the admin work. On this page the admin can view, add and change data buyers of new fuel. So each purchaser of fuel is required to register to receive the ID that was registered by the administrator to the database. Administrators for the main display page can be seen in Figure 8.

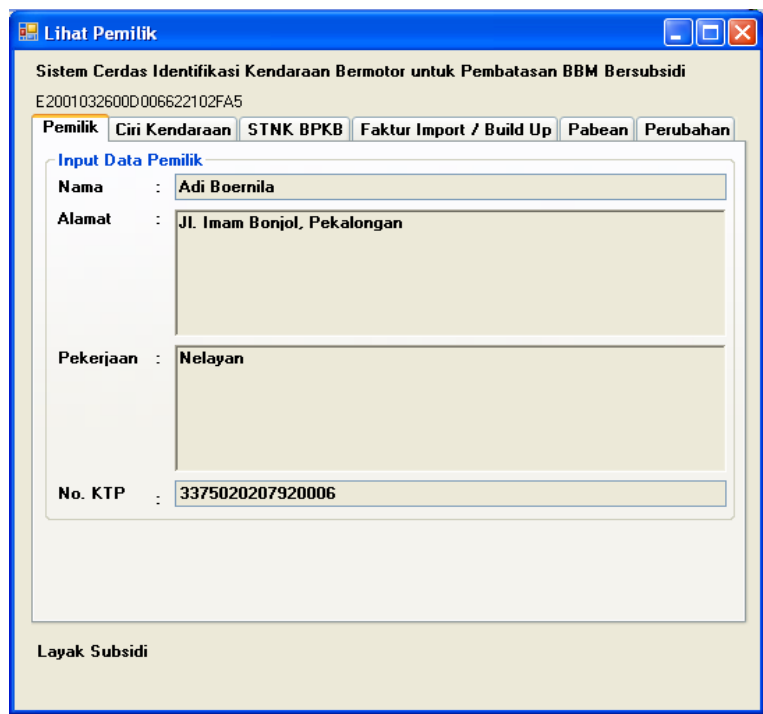

Fig 7: Vehicle Owner Form

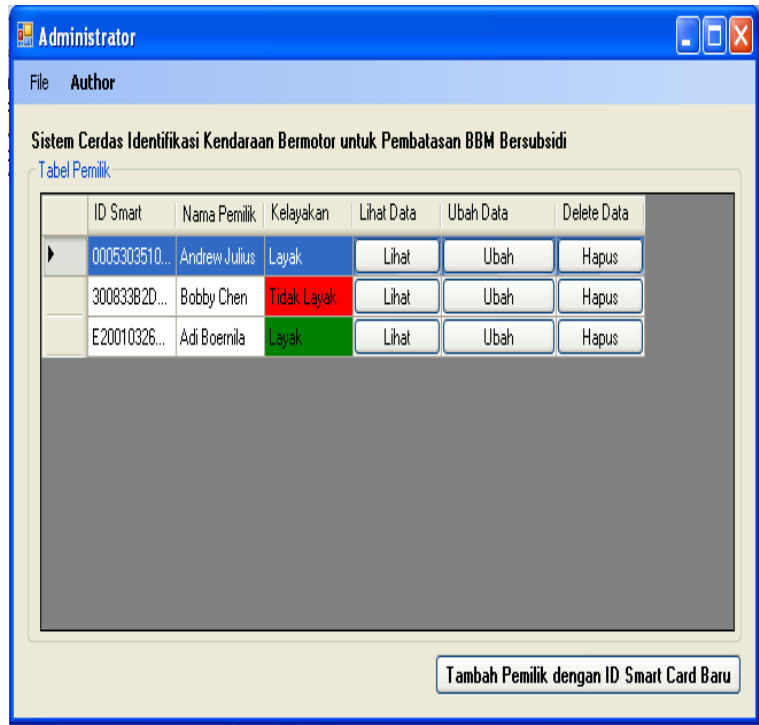

Fig 8:. Administrator Form

To view the data administrator can just press the button "Lihat" on each data record, and will display the Data View page as shown in Figure 7. To change the data administrators can simply press the "Ubah" in the data record to be changed and it will display the page Change data as shown in Figure 9. After completing the data to be changed, then the user can just press the "Ganti" to change the data, or press "Batal" to cancel. Furthermore, if you want to delete, then simply press the "Delete" on the record to be deleted. To add data to the owner / buyer of fuel admins can press the button "Add Owner with New Smart Card ID" and must perform a scan Smart Card ID to be added to the new data. See Figure 10. Once you have selected, then the administrator can begin to incorporate new data to be added and press the "Save" button to add data to the database. See Figure 11.

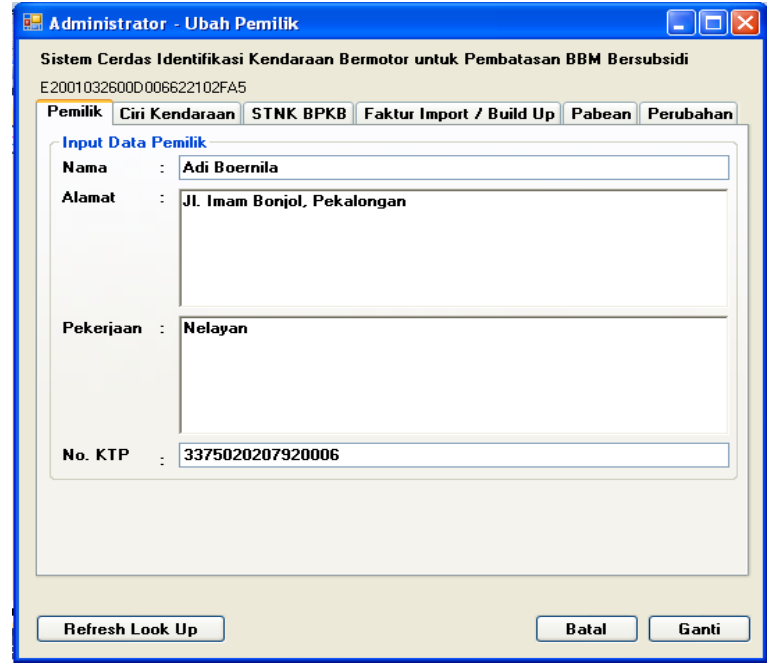

Fig 9: Edit Vehicle Owner Form

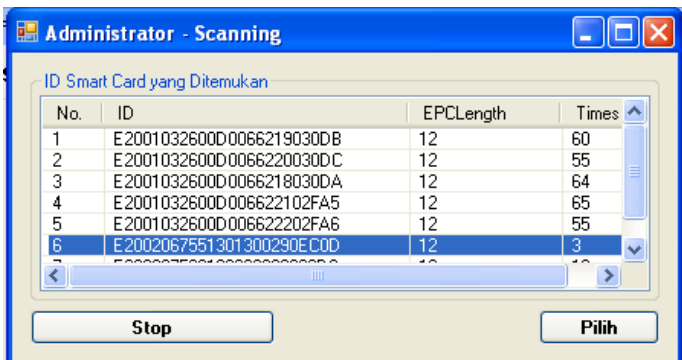

Fig 10: Scanning Process Form

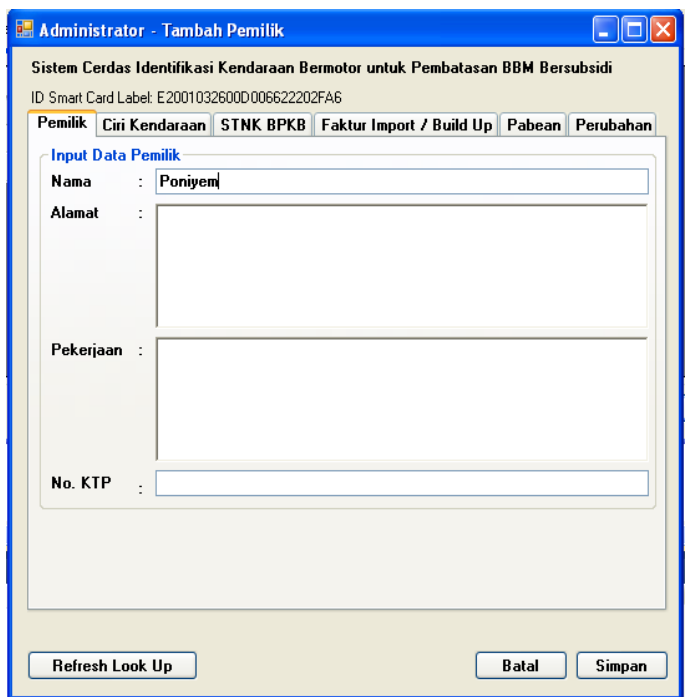

Fig 11: Data Entry Form

\section{CONCLUSION}

From the research, it was found that the data stored in the smart label can be used to display the status of the vehicle's fuel subsidy. The data stored in the smart label is the same as vehicle registration data, and the data which is used to determine the status of the vehicle subsidy are the year of manufacture, the cylinder capacity and the type of vehicle registration.

\section{ACKNOWLEDGMENTS}

The authors wish to acknowledge the financial support of the Directorate General of Higher Education of Republic of Indonesia to accomplish this research. 


\section{REFERENCES}

[1] E. Prastyo. (2012, Jul.) Suara Surabaya. [Online]. http://kelanakota.suarasurabaya.net/news/2012/108730Pertamina-:-3-Kendaraan-Ini-Dilarang-Minum-BBMBersubsidi

[2] E. S. Toyudho. (2013, Feb.) Tempo.co. [Online]. http://www.tempo.co/read/news/2013/02/24/058463295/I ni-Cara-Pangkas-Subsidi-BBM-Tanpa-Diprotes

[3] S. Ahson, RFID Handbook. America: CRC Press Taylor \& Francis Group, 2008.

[4] A. C. D. Cartasegna, et al., "Smart RFID Label for Monitoring the Preservation Conditions of Food," in IEEE International Symposium on Circuits and Systems, Taipei, 2009, pp. 1161-1164.

[5] D. Briand, F. Molina-Lopez, A. V. Quintero, G. Mattana, and N. F. d. Rooij, "Printed Sensors on Smart RFID Labels for Logistics," in New Circuits and Systems Conference (NEWCAS), 2012, pp. 449-452.

[6] V. Todorovica, M. Neag, and M. Lazarevica, "On the Usage of RFID Tags for Tracking and Monitoring of Shipped Perishable Goods," in 24th DAAAM International Symposium on Intelligent Manufacturing and Automation, 2013, pp. 1345-1349.
[7] S. Y. C. a. P. Hsu, "CPW-Fed Folded-Slot Antenna for $5.8 \mathrm{GHz}$ RFID Tags," Electronic Letters, vol. 24, p. 1516-1517, 2004.

[8] M. Hirvonen, P. Pursula, K. Jaakkola, and K. Laukkanen, "Planar Inverted-F Antenna for Radio Frequency Identification," Electronic Letters, vol. 40, p. 848-850, 2004.

[9] Q. Xianming and Y. Ning, "A Folded Dipole Antenna for RFID," in Proceedings of IEEE Antennas and Propagation Society International Symposium, 2004, p. 97-100.

[10] K. S. Leong, M. L. Ng, D. M. Hall, and P. H. Cole, "A Small Passive UHF RFID Tag for Livestock Identification," in IEEE 2005 International Symposium on Microwave, Antenna, Propagation and EMC Technologies for Wireless Communications, 2005, p. 6770.

[11] E. F. P. Abad, et al., "RFID Smart Tag for Traceability and Cold Chain Monitoring of Foods: Demonstration in an Intercontinental Fresh Fish Logistic Chain," Journal of Food Engineering, vol. 93, no. 4, p. 394-399, 2009. 